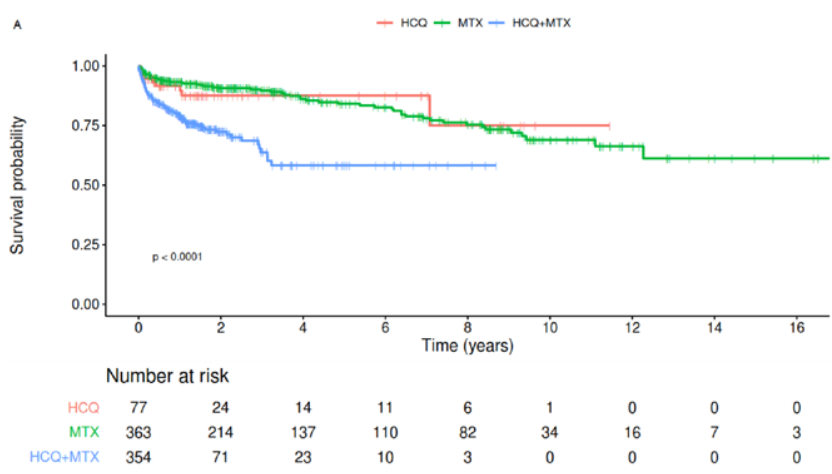

B

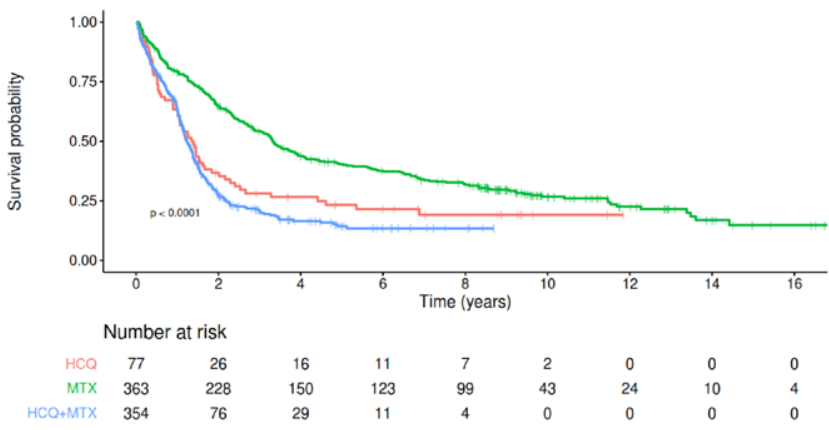

Figure 1. Kaplan-Meier curves of MTX and HCQ monotherapies and MTX+HCQ combination therapy, with (a) survival to first ADR and (b) drug survival.

Conclusion: Patients using $\mathrm{MTX}+\mathrm{HCQ}$ combination therapy are more likely to experience an ADR during the first time drug use compared to MTX and $\mathrm{HCQ}$ monotherapies. MTX+HCQ combination therapy also leads to experiencing an ADR sooner compared to both monotherapies. Drug survival of patients treated with $\mathrm{HCQ}$ monotherapy as well as $\mathrm{MTX}+\mathrm{HCQ}$ combination therapy is shorter compared to MTX monotherapy.

Disclosure of Interests: Kimberly Velthuis: None declared, My Nguyen: None declared, Joep Scholl: None declared, Jurriaan Jansen: None declared, Jette van Lint: None declared, Peter ten Klooster: None declared, Harald Vonkeman Consultant of: BMS, Celgene, Celltrion, Galapagos, Gilead, Janssen-Cilag, Lilly, Novartis, Pfizer, Sanofi-Genzyme, Grant/research support from: Abbvie, Naomi Jessurun: None declared

DOI: 10.1136/annrheumdis-2021-eular.181

\section{POS0649 BARICITINIB PROVIDES GREATER IMPROVEMENTS IN PATIENT-REPORTED OUTCOMES ACROSS ALL DISEASE ACTIVITY LEVELS COMPARED TO PLACEBO AND ADALIMUMAB IN RHEUMATOID ARTHRITIS}

P. C. Taylor ${ }^{1}$, R. Blanco ${ }^{2}$, K. Ikeda ${ }^{3}$, B. Jia ${ }^{4}$, Y. F. Chen ${ }^{4}$, C. Walls ${ }^{4}$, E. Haladyj ${ }^{4}$, B. Fautrel ${ }^{5} .{ }^{1}$ University of Oxford, Botnar Research Centre, Nuffield Department of Orthopaedics, Rheumatology and Musculoskeletal Sciences, Oxford, United Kingdom; ${ }^{2}$ Hospital Universitario Marqués de Valdecilla, Department of Rheumatology, Santander, Spain; ${ }^{3}$ Chiba University Hospital, Department of Allergy and Clinical Immunology, Chiba, Japan; ${ }^{4}$ Eli Lilly and Company, Lilly Research Laboratories, Indianapolis, United States of America; ${ }^{5}$ Sorbonne University - Assistance Publique Hôpitaux de Paris, Pitie Salpetriere Hospital, Rheumatology Department, Paris, France

Background: Baricitinib (BARI) is a JAK1/JAK2 inhibitor which provides improvements to clinical signs, symptoms, and patient-reported outcomes (PROs) in patients with rheumatoid arthritis $[1,2]$

Objectives: The effect of BARI on the relationship between disease activity and pain has been explored previously [3]. The purpose of this post hoc analysis was to determine the association between additional PROs (physical function, fatigue, and duration of morning joint stiffness) and disease activity status after 12 weeks of treatment and to evaluate whether patients with an inadequate response to methotrexate treated with BARI $4 \mathrm{mg}$ experienced greater PRO improvement than patients treated with either placebo (PBO) or adalimumab (ADA) across all levels of disease activity.

Methods: Data for these analyses were derived from the Phase 3 study RA-BEAM ( $\mathrm{N}=1305$; NCT01710358). Pain was evaluated using a $0-100 \mathrm{~mm}$ visual analog scale, physical function was assessed using the Health Assessment Questionnaire-Disability Index (HAQ-DI), fatigue was measured using the Functional Assessment of Chronic Illness Therapy-Fatigue (FACIT-F) scale, and duration of morning joint stiffness (MJS, minutes) was reported by the patient. Disease activity was measured using the Clinical Disease Activity Index (CDAl) and categorized as remission (REM, $\leq 2.8$ ), low disease activity (LDA, >2.8 to $\leq 10$ ), moderate disease activity (MDA, $>10$ to $\leq 22$ ), or high disease activity (HDA, >22). Linear regression was used to model the relationship between change in PROs at Week 12 (response) and CDAl values at Week 12 (primary explanatory variable) to evaluate the extent of improvement in PROs with BARI relative to $\mathrm{PBO}$ and $A D A$ across a spectrum of disease activity levels. Last observation carried forward was used to impute missing values.

Results: At baseline, $91 \%$ of patients were classified as having HDA and $9 \%$ as having MDA by CDAI across all treatment groups. After 12 weeks of treatment, $2 \%, 7 \%$, and $9 \%$ of patients achieved REM; $16 \%, 27 \%$, and $33 \%$ of patients achieved LDA; and $33 \%, 40 \%$, and $38 \%$ of patients achieved MDA with PBO, ADA, and BARI, respectively [3].

At Week 12, the estimated changes in measures of pain and physical function, as well as duration of MJS, for BARI $4 \mathrm{mg}$ were greater than both PBO and ADA at all disease activity level threshold values of CDAI (Table 1). The estimated change in fatigue for BARI $4 \mathrm{mg}$ was similar to that of ADA, and greater than PBO, at all disease activity level threshold values (Table 1).

Table 1. Estimate of PRO Improvement by Disease Activity Threshold Level (CDAI) at Week 12

\begin{tabular}{|c|c|c|c|c|c|c|c|c|c|}
\hline \multirow[t]{2}{*}{ PRO } & \multicolumn{3}{|c|}{$\mathrm{CDAl}=2.8$} & \multicolumn{3}{|c|}{$\mathrm{CDAl}=10$} & \multicolumn{3}{|c|}{$\mathrm{CDAl}=22$} \\
\hline & PBO & ADA & $\begin{array}{l}\text { BARI } \\
4 \mathrm{mg}\end{array}$ & PBO & ADA & BARI $4 \mathrm{mg}$ & РBO & ADA & BARI $4 \mathrm{mg}$ \\
\hline Pain VAS ${ }^{a}(\mathrm{~mm})$ & -28.4 & -37.9 & -40.9 & -24.5 & -32.6 & -36.1 & -18.0 & -23.7 & -28.1 \\
\hline$H A Q-D I^{b}$ & -0.6 & -0.7 & -0.9 & -0.5 & -0.7 & -0.7 & -0.4 & -0.5 & -0.6 \\
\hline FACIT-F ${ }^{c}$ & 9.8 & 11.8 & 11.1 & 8.8 & 10.6 & 10.2 & 7.0 & 8.7 & 8.7 \\
\hline Duration of MJS ( $\mathrm{min})$ & -6.9 & -37.8 & -64.9 & -6.3 & -35.3 & -55.7 & -5.3 & -31.3 & -40.2 \\
\hline
\end{tabular}

${ }^{\text {aPain } V A S ~ s c o r e s ~ r a n g e ~ f r o m ~} 0$ (no pain) to 100 (worst pain).

bHAQ-DI scores range from 0 (no disability) to 3 (completely disabled).

${ }^{\mathrm{C}} \mathrm{FACIT-F}$ scores range from 0 (worst fatigue) to 52 (no fatigue)

Abbreviations: ADA, adalimumab; BARI, baricitinib; CDAI, Clinical Disease Activity Index FACIT-F, Functional Assessment of Chronic Illness Therapy-Fatigue; HAQ-DI, Health Assessment Questionnaire-Disability Index; MJS, morning joint stiffness; PBO, placebo; PRO, patient-reported outcomes; VAS, visual analog scale.

Conclusion: Estimates of treatment differences suggest that patients treated with BARI 4 mg may experience greater improvements in pain, physical function and MJS duration than patients treated with PBO or ADA regardless of their disease activity status reached after 12 weeks of treatment. Using this approach improvements in fatigue with BARI $4 \mathrm{mg}$ may be greater than with $\mathrm{PBO}$ and similar to ADA after 12 weeks.

\section{REFERENCES:}

[1] Taylor, P.C., et al., N Engl J Med, 2017. 376(7): p. 652-662.

[2] Keystone, E.C., et al., Ann Rheum Dis, 2017. 76(11): p. 1853-1861.

[3] Taylor, P., et al., Arthritis Rheumatol, 2019. 71(S10): p. 2455-2457.

Acknowledgements: The authors would like to acknowledge Catherine Lynch with Eli Lilly and Company, for medical writing and project management support. Disclosure of Interests: Peter C. Taylor Consultant of: AbbVie, Biogen, Galapagos, Gilead, GlaxoSmithKline, Janssen, Eli Lilly, BMS, Pfizer, Roche, Celltrion, Sanofi, Nordic Pharma, Fresenius and UCB, Grant/research support from: Celgene, Galapagos, Gilead, Eli Lilly, Ricardo Blanco Speakers bureau: Abbvie, Pfizer, Roche, BMS, Janssen, Eli Lilly and MSD, Consultant of: Abbvie, Pfizer, Roche, BMS, Janssen, Eli Lilly and MSD, Grant/research support from: Abbvie, MSD, and Roche, Kei Ikeda Speakers bureau: Eli Lilly, Abbvie, Mitsubishi-Tanabe, Novartis, Paid instructor for: Abbvie, Grant/research support from: Mitsubishi-Tanabe, Bochao Jia Shareholder of: Eli Lilly and Company, Employee of: Eli Lilly and Company, Yun-Fei Chen Shareholder of: Eli Lilly and Company, Employee of: Eli Lilly and Company, Chad Walls Shareholder of: Eli Lilly and Company, Employee of: Eli Lilly and Company, Ewa Haladyj Employee of: Eli Lilly and Company, Bruno Fautrel Speakers bureau: Eli Lilly, Consultant of: AbbVie, Biogen, Bristol-Myers Squibb, Celgene, Janssen Pharmaceuticals, Eli Lilly and Company, Medac, MSD, NORDIC Pharma, Novartis, Pfizer Inc., Roche, SanofiAventis, SOBI, UCB, Grant/research support from: AbbVie, Eli Lilly and Company, MSD, Pfizer Inc

DOI: 10.1136/annrheumdis-2021-eular.182

\section{POS0650 PREDICTORS OF DURABLE CLINICAL RESPONSE TO TOFACITINIB 11 MG ONCE DAILY WITH OR WITHOUT METHOTREXATE IN PATIENTS WITH RHEUMATOID ARTHRITIS: POST HOC ANALYSIS OF DATA FROM A PHASE 3B/4 METHOTREXATE WITHDRAWAL STUDY}

K. Yamaoka ${ }^{1}$, S. B. Cohen ${ }^{2}$, N. Sugiyama ${ }^{3}$, H. Shi ${ }^{4}$, J. L. Rivas ${ }^{5}$, A. Diehl ${ }^{4}$, J. S. Smolen ${ }^{6} .{ }^{1}$ Kitasato University, Department of Rheumatology and Infectious Diseases, Sagamihara, Japan; ${ }^{2}$ Metroplex Clinical Research Center, Dallas, 
TX, United States of America; ${ }^{3}$ Pfizer Japan Inc, Inflammation and Immunology, Tokyo, Japan; ${ }^{4}$ Pfizer Inc, Inflammation and Immunology, Collegeville, PA, United States of America; ${ }^{5}$ Pfizer SLU, Inflammation and Immunology, Madrid, Spain; ${ }^{6}$ Medical University of Vienna, Department of Rheumatology, Vienna, Austria

Background: ORAL Shift, a global Phase $3 \mathrm{~b} / 4$ non-inferiority study, demonstrated sustained efficacy and safety of tofacitinib modified-release (MR) $11 \mathrm{mg}$ once daily (QD) following methotrexate (MTX) withdrawal in patients with rheumatoid arthritis (RA) who achieved Clinical Disease Activity Index (CDAl) low disease activity (LDA) after treatment with tofacitinib + MTX.

Objectives: To assess predictors of durable clinical response in patients receiving tofacitinib MR $11 \mathrm{mg}$ QD in ORAL Shift.

Methods: ORAL Shift (NCT02831855) enrolled patients aged $\geq 18$ years with moderate to severe RA and an inadequate response to MTX. Patients received open-label tofacitinib MR $11 \mathrm{mg}$ QD + MTX for 24 weeks. Patients achieving LDA (CDAl score $\leq 10$ ) at Week (W)24 entered the 24-week double-blind MTX withdrawal phase and were randomised 1:1 to receive tofacitinib MR $11 \mathrm{mg} Q D+$ placebo (tofacitinib monotherapy; ie blinded MTX withdrawal) or continue tofacitinib + MTX. In this post hoc analysis of randomised patients, we assessed predictors of durable response (maintenance of response from W24-48) per CDAI LDA and remission (CDAl score $\leq 2.8$ ) criteria. All covariates were initially assessed for significance in a univariate logistic regression. Highly correlated covariates were reviewed to assess which would be removed prior to modelling in a multivariable logistic regression. Remaining significant $(p \leq 0.10)$ covariates in the univariate regression were selected in the model using a stepwise selection process with $p \leq 0.15$ entry and $p \leq 0.05$ stay criteria. From the final model, estimated odds ratios (ORs) with $95 \%$ confidence intervals (Cls) are presented.

Results: In the double-blind phase of ORAL Shift, durable CDAI LDA and remission rates were: $66.2 \%$ and $14.7 \%$, respectively, with tofacitinib + MTX ( $\mathrm{N}=266)$; and $55.3 \%$ and $11.0 \%$, respectively, with tofacitinib + placebo $(\mathrm{N}=264)$ (Table 1$)$. In the multivariable analysis, five patient covariates significantly predicted durable CDAI LDA (Figure 1; discussed hereafter). Each unit increase in CDAI score at W24 reduced the likelihood of maintaining CDAI LDA by $22.0 \%$. Each unit increase in C-reactive protein (CRP) at W24 increased the likelihood of maintaining CDAI LDA by $4.0 \%$; this may have been due to imbalanced CRP levels at W24 (randomisation) between treatment groups (Figure 1, footnote $\mathrm{C}$ ). The odds of durable CDAI LDA were $53.0 \%$ lower in the US vs Europe and $61.0 \%$ lower in the US vs 'other' regions. Each unit increase in baseline Health Assessment Questionnaire-Disability Index (HAQ-DI) score reduced the odds of durable CDAI LDA by $34.0 \%$. Patients receiving tofacitinib + MTX had $66.0 \%$ greater odds of durable CDAI LDA vs patients receiving tofacitinib + placebo. CDAI at W24 was the only significant predictor of durable CDAI remission in the multivariable analysis: $\mathrm{OR}(95 \% \mathrm{Cl}) 0.32(0.24,0.43)$; $\mathrm{p}<0.0001$. Each unit increase in CDAl score at W24 reduced the odds of durable CDAl remission by $68.0 \%$.

Table 1. Durable CDAI LDA and remission ${ }^{\mathrm{a}}$ in patients receiving tofacitinib MR $11 \mathrm{mg}$ QD with MTX or placebo in the double-blind phase of ORAL Shift

\begin{tabular}{lcc}
\hline & $\begin{array}{c}\text { Tofacitinib + MTX } \\
(\mathbf{N}=\mathbf{2 6 6 )}\end{array}$ & $\begin{array}{c}\text { Tofacitinib + placebo } \\
\mathbf{( N = 2 6 4 )}\end{array}$ \\
\hline Durable CDAI LDA, $\mathrm{n}(\%)$ & $176(66.2)$ & $146(55.3)$ \\
Durable CDAI remission, $\mathrm{n}(\%)$ & $39(14.7)$ & $29(11.0)$
\end{tabular}

aDurable CDAI LDA or remission was defined as achievement of LDA (CDAI score $\leq 10$ ) or remission (CDAl score $\leq 2.8$ ), respectively, at W24-48

$\mathrm{N}$, number of patients in each group; $n$, number of patients achieving outcome
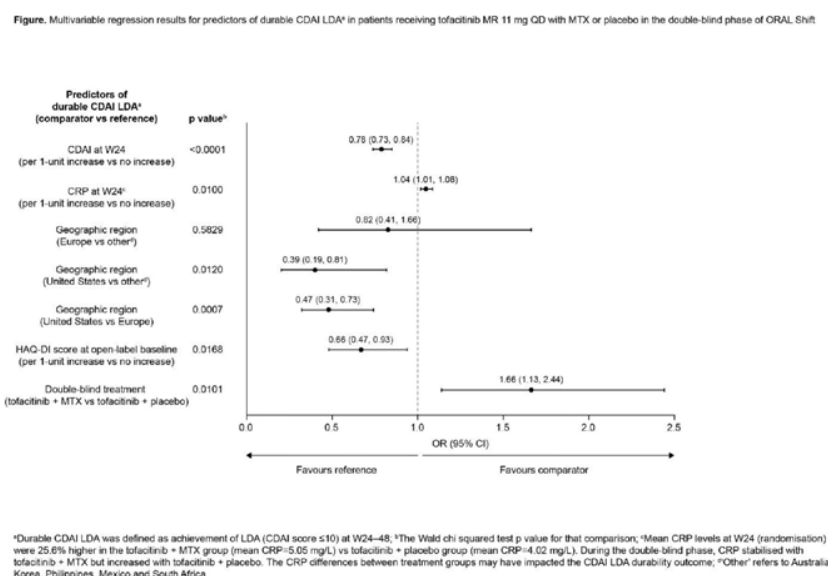

Conclusion: This post hoc analysis of data from ORAL Shift found that CDAI and CRP at W24, geographic region, baseline HAQ-DI and treatment could be predictors for durable CDAI LDA. As these findings were limited to patients who achieved CDAI LDA at W24 with tofacitinib MR $11 \mathrm{mg}$ QD + MTX, additional data in the general patient population need to be investigated. REFERENCES:

[1] Cohen et al. Lancet Rheumatol 2019; 1: E23-34.

Acknowledgements: Study sponsored by Pfizer Inc. Medical writing support was provided by Sarah Piggott, CMC Connect, and funded by Pfizer Inc.

Disclosure of Interests: Kunihiro Yamaoka Speakers bureau: Actelion, Astellas, Chugai, Eisai, Eli Lilly, GlaxoSmithKline, Janssen, Mitsubishi Tanabe, Nippon Shinyaku, Pfizer Inc, Takeda, Consultant of: Actelion, Astellas, Chugai, Eisai, El Lilly, GlaxoSmithKline, Janssen, Mitsubishi Tanabe, Nippon Shinyaku, Pfizer Inc Takeda, Stanley B. Cohen Consultant of: AbbVie, Eli Lilly, Genentech, Gilead Sciences, Pfizer Inc, Grant/research support from: AbbVie, Eli Lilly, Genentech, Gilead Sciences, Pfizer Inc, Naonobu Sugiyama Shareholder of: Pfizer Inc Employee of: Pfizer Inc, Harry Shi Shareholder of: Pfizer Inc, Employee of: Pfize Inc, Jose Luis Rivas Shareholder of: Pfizer Inc, Employee of: Pfizer Inc, Annette Diehl Shareholder of: Pfizer Inc, Employee of: Pfizer Inc, Josef S. Smolen Consultant of: AbbVie, AstraZeneca, Celgene, Celltrion, Chugai, Eli Lilly, Gilead Sciences, ILTOO, Janssen, Novartis-Sandoz, Pfizer Inc, Roche, Samsung Sanofi, Grant/research support from: AbbVie and AstraZeneca DOI: 10.1136/annrheumdis-2021-eular.357

\section{POS0651 CLINICAL AND FUNCTIONAL RESPONSE TO TOFACITINIB IN PATIENTS WITH RHEUMATOID ARTHRITIS: PROBABILITY PLOT ANALYSIS OF RESULTS FROM A 48-WEEK PHASE 3B/4 METHOTREXATE WITHDRAWAL STUDY}

S. B. Cohen ${ }^{1}$, Y. H. Chen ${ }^{2}$, N. Sugiyama ${ }^{3}$, J. L. Rivas ${ }^{4}$, A. Dieh $l^{5}$, T. Lukic ${ }^{6}$, J. Paulissen ${ }^{6}$, H. Fan ${ }^{5}$, T. Hirose ${ }^{3}$, E. Keystone $e^{7}{ }^{1}$ Metroplex Clinical Research Center, Dallas, TX, United States of America; ${ }^{2}$ Taichung Veterans General Hospital, Division of Allergy, Immunology, and Rheumatology, Taichung, Taiwan, Republic of China; ${ }^{3}$ Pfizer Japan Inc, Inflammation and Immunology, Tokyo, Japan; ${ }^{4}$ Pfizer SLU, Inflammation and Immunology, Madrid, Spain; ${ }^{5}$ Pfizer Inc, Inflammation and Immunology, Collegeville, PA, United States of America; ${ }^{6}$ Pfizer Inc, Inflammation and Immunology, New York, NY, United States of America; ${ }^{7}$ Mount Sinai Hospital, Toronto, ON, Canada

Background: The Phase 3b/4 study ORAL Shift (NCT02831855) demonstrated sustained efficacy/safety of tofacitinib modified-release $11 \mathrm{mg}$ QD following MTX withdrawal, that was non-inferior to continued tofacitinib + MTX use, in patients (pts) with moderate to severe RA who achieved LDA with tofacitinib + MTX at Week (W) $24 .^{1}$

Objectives: To assess differences and similarities in clinical/functional responses in pts receiving tofacitinib \pm MTX in ORAL Shift.

Methods: In ORAL Shift, pts received open-label tofacitinib + MTX to W24 at W24, pts who achieved CDAI LDA were randomised to receive tofacitinib + MTX or tofacitinib + placebo (PBO) from W24-48. In this post hoc analysis, clinical efficacy endpoints were ACR-N (minimum \% change from baseline $[\mathrm{BL} ; \Delta]$ at W48 achieved by each pt in 3 efficacy measures), $\triangle \mathrm{DAS} 28-4(\mathrm{ESR})$ and DAS28-4(ESR) remission/LDA (scores $\leq 3.2$ ) and moderate/high disease activity (scores >3.2). Functional efficacy endpoints were $\triangle H A Q-D$ and HAQ-DI clinically relevant functional progression (CRFP) status at W48, defined as failure to achieve improvement in $\mathrm{HAQ}-\mathrm{DI} \geq$ minimum clinically important difference (MCID; $\geq 0.22$ decrease from $B L$ in $H A Q-D I)$. Thus, CRFP was defined as $<0.22$ decrease, no change or increase from $B L$ in HAQ-DI at W48. All efficacy endpoints were summarised descriptively. Cumulative probability plots of ACR-N and $\triangle \mathrm{HAQ}-\mathrm{DI}$ were produced. Median of mean CRP values from BL-W24 and >W24-48 were assessed by response subgroups.

Results: 266 pts receiving tofacitinib + MTX and 264 pts receiving tofacitinib + PBO in W24-48 were included. At W48: mean ACR-N was numerically greater with tofacitinib + MTX vs tofacitinib + PBO (60.8 vs 53.1$)$; mean decrease in $\mathrm{HAQ}$-DI was generally similar between groups (-0.71 vs -0.67$)$; mean decrease in DAS28-4(ESR) was numerically greater with tofacitinib + MTX vs tofacitinib + PBO (-2.95 vs -2.68). The differences/similarities between groups in ACR- $N$ and $\triangle \mathrm{HAQ}$-DI were also seen in cumulative probability plots (Figure 1). CRFP rates were numerically lower with tofacitinib + MTX $(18.7 \%)$ vs tofacitinib + PBO $(23.5 \%)$, and in pts with remission/LDA (tofacitinib + MTX, 12.1\%; tofacitinib + PBO, $16.8 \%$ ) vs moderate/high disease activity (tofacitinib + MTX, 26.2\%; tofacitinib + PBO, $30.8 \%$ ). Median of mean CRP over time was generally numerically lower in pts with CRFP vs non-CRFP and DAS28-4(ESR)-defined remission/ LDA vs moderate/high disease activity; and in those receiving tofacitinib + PBO vs tofacitinib + MTX, irrespective of CRFP or DAS28-4(ESR) disease status (Table 1). 